\title{
AN ANP APPROACH FOR COMPETITIVENESS ANAL YSIS IN BUSINESS SECTORS. THE CASE OF VENEZUELA
}

\author{
Rocío Poveda-Bautista* \\ Universidad Politécnica de Valencia \\ Departamento de Proyectos de Ingeniería \\ Camino de vera s/n 46022 Valencia (SPAIN) \\ E-mail: ropobau@upvnet.upv.es \\ Doris C. Baptista C. \\ Univers idad Metropolitana \\ Departamento de Procesos y Sistemas \\ Caracas 1071, Edo Miranda, Venezuela \\ E-mail: dbaptista@unimet.edu.ve \\ Mónica García-Melón \\ Univers idad Politécnica de Valencia \\ Departamento de Proyectos de Ingeniería \\ Camino de vera s/n 46022 Valencia (SPAIN) \\ E-mail: $\underline{\text { mgarciam@,dpi.upv.es }}$
}

\begin{abstract}
In this paper a new approach to assess companies' competitiveness performance by means of indicators in an efficient and reliable way is presented. The approach combines the use of the Analytic Network Process (ANP) method with the Balance Scorecard and the information obtained from sectorial experts during the decision - making process. The ANP method allows the aggregation of experts' judgments on each of the selected indicators used into one company competitiveness index. For that, a comparative study for competitiveness indicators has been carried out among three different business sectors representative of Venezuela.

Keywords: Multicriteria, ANP, Benchmarking, Competitiveness.
\end{abstract}

\section{Introduction}

Competitiveness, Benchmarking and Management Systems are approaches used by companies since the end of the 20th century which contribute to the improvement of a company, Business sector or country with the aim of becoming competitive.

The concept of Benchmarking now refers not only to comparing the company with its 'neighbours' but also to determining the competitiveness indicators used for comparison analys is and their impact on the competitiveness measurement of the companies.

In the past, entrepreneurial competitiveness measurement only depended on financial indicators. But recently it also includes factors such as innovation, learning and entrepreneurial capabilities as well as management indicators.

Porter (1997) defines competitiveness as the ability of a business to systematically maintain the differentiating advantages that allow it to reach, sustain and improve a given socioeconomic position. Porter's approach assumes that every company that competes in an Business sector possesses a competitive strategy. Based on this second assumption, the value chain can be defined as a conceptual

\footnotetext{
* Corresponding author
} 
structure that helps to diagnose the sources of competitive advantage. In this sense business analysis is based on the analys is of the company's value chain.

Augusto et al. (2006) say that in highly competitive market the organization must engage in a systematic benchmarking process aiming at enhancing performance in the context of continuous improvement. For this end, the organization should possess a benchmarking system that includes a planned model that measures the characteristics and parameters of multifaceted performance. Any competitive benchmarking system should contain a number of specific indicators approved by experts.

On the other hand, authors like Thakkar et al. (2007) propose the use of Management Systems as analys is tools that help relate the company's competitive strategy to its performance indicators. These authors consider that the Balanced Scorecard model (BSC) provides an appropriate framework to translate the company's strategic objectives to a set of coherent performance indicators. The main advantage of BSC is the close relationship between the company's strategic and the different internal and external, financial and non-financial indicators clusters, grouped into 4 perspectives: Customer, Learning and Growth, Internal Business Processes and Financial.

To help managers to assess the Competitiveness Indicators (CIs) within a business sector a new multicriteria approach (MCDA) based on the Analytic Network Process (ANP) technique and the participation of a group of experts is proposed.

\section{Methodology}

The methodology proposed in this study applies Competitive Benchmarking to each Business sector, following Ellis et al. (2002), who suggest that the components of Benchmarking depend on the type of Business sector and the competitiveness level perceived by each sector. This methodology allows the definition of a number of CIs based on the performance and setting of an Business sector, and their implicit relationships. In this way it is possible to establish a prioritization of the CIs ordered by their competitiveness impact within that particular Business sector and to compare these CIs among the analyzed sectors.

The methodology proposed here is based on three main aspects: the competitiveness model defined by Porter (1995), the BSC system developed by Kaplan and Norton (2000) and the multi-criteria ANP model developed by Thomas Saaty (2005) which allows modelling the decision problem as a network of interrelated elements (indicators) and works well in scenarios where there is little or no quantitative information, like in competitiveness measurement processes. Figure 1 shows the five stages of the methodology proposed in this study:

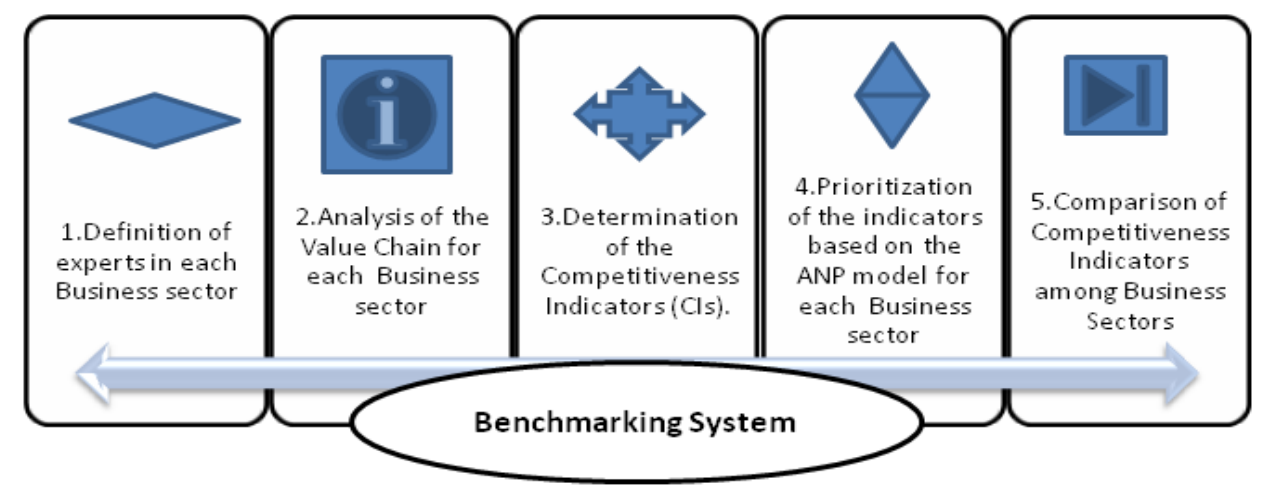

Figure 1. Proposed Methodology

\section{Case studies}

The methodology was applied in three business sectors in Venezuela empirically chosen outside the primary sector: Oil. The sectors are: Advertising, Agricultural and livestock and Dairy. 
Case 1: The Advertising sector is referred to agencies that offer services of Publicity, both Venezuelan and foreign. In this type of industry, the value chain has the three following main areas: Recruitment of Media, Creative Department and Accounts Department. Figure 2 shows the value chain.

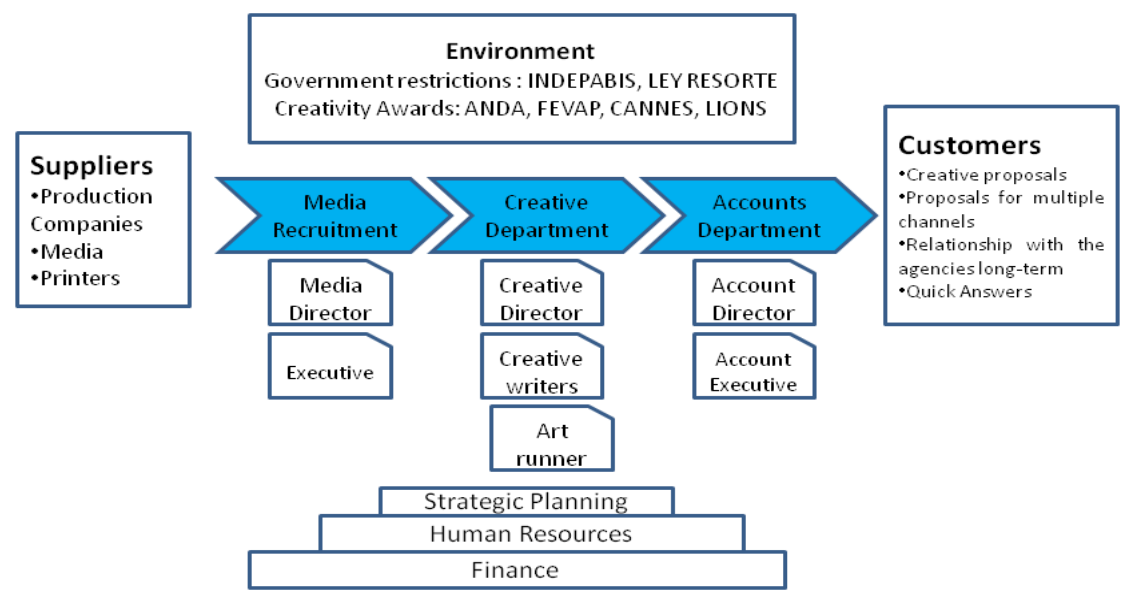

Figure 2. Value Chain of the Advertising sector.

For Advertising sector enterprises, it is very important their recognition through national and international awards. Figure 3 shows the pre-selected 15 indicators grouped under the ANP model.

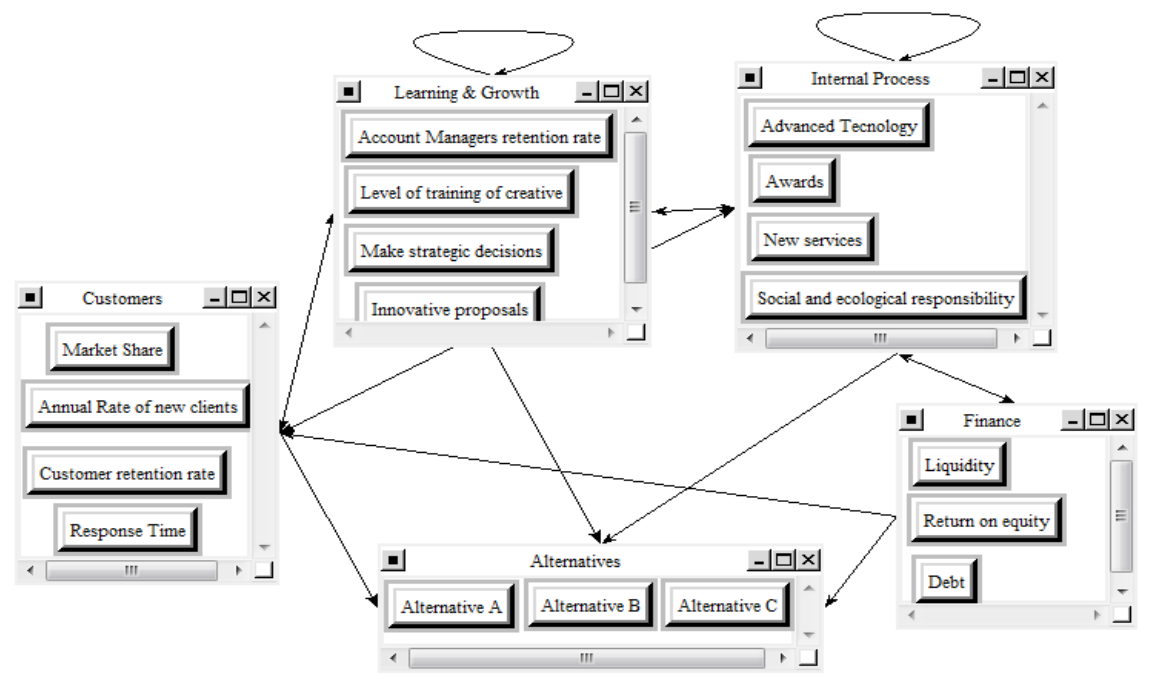

Figure 3 Diagram of influences of the Advertising Model.

Table 1 shows that only seven of the 15 pre-selected indicators are important in the Advertising sector competitiveness. Level of training of creative staff and New Services stand out as the most important.

Table 1 Indicators of competitiveness for the Advertising Sector. 


\begin{tabular}{|l|r|l|r|}
\hline \multicolumn{1}{|c|}{ Indicator } & Weight & \multicolumn{1}{|c|}{ Indicator } & Weight \\
\hline Level of training of creative staff & $38,2 \%$ & new services & $34,8 \%$ \\
\hline Advance Tecnology & $8,7 \%$ & make strategic decisions & $6,5 \%$ \\
\hline Response Time & $6,0 \%$ & Awards & $3,2 \%$ \\
\hline Account managers retention rate & $1,3 \%$ & Innovative proposals & $0,5 \%$ \\
\hline Customer retention rate & $0,3 \%$ & Market Share & $0,3 \%$ \\
\hline Annual rate of new clients & $0,1 \%$ & $\begin{array}{l}\text { Social and } \\
\text { responsibility }\end{array}$ & $0,0 \%$ \\
\hline Return on equity & $0,0 \%$ & Debt & $0,0 \%$ \\
\hline Liquidity & $0,0 \%$ & & \\
\hline
\end{tabular}

Case 2. The second sector under study is the Agricultural and Livestock one specifically in the meat chain, -hereinafter referred Meat Industry-. In Venezuela there are 44 enterprises, which account for $80 \%$ of the meat for the country. The supply of beef does not meet national demand. For this reason, is imported from Brazil in order to meet internal demand. The industry value chain is shown in Figure 4.

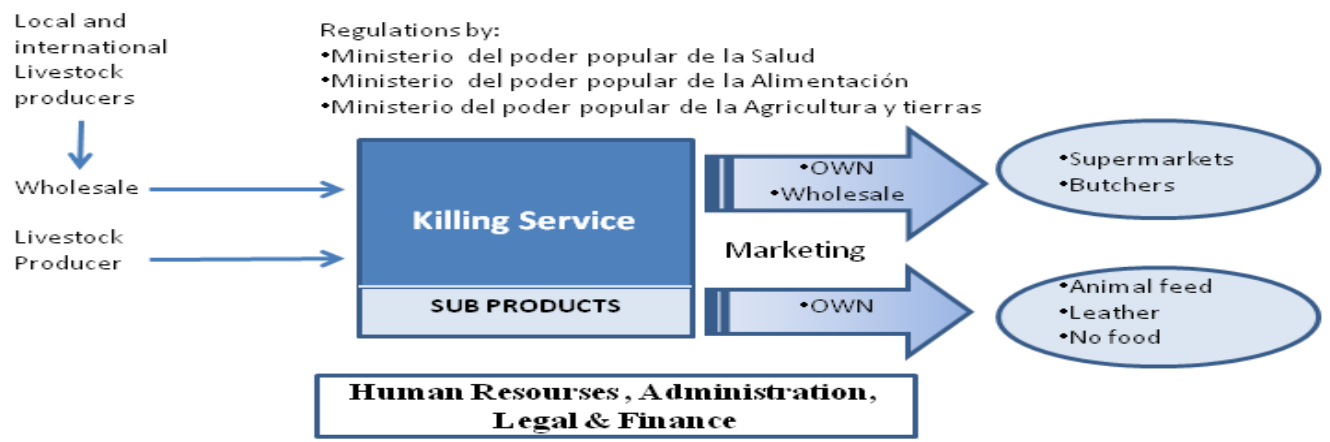

Figure 4. Value Chain of Meat Industry.

Below in Figure 5 the ANP model is shown.

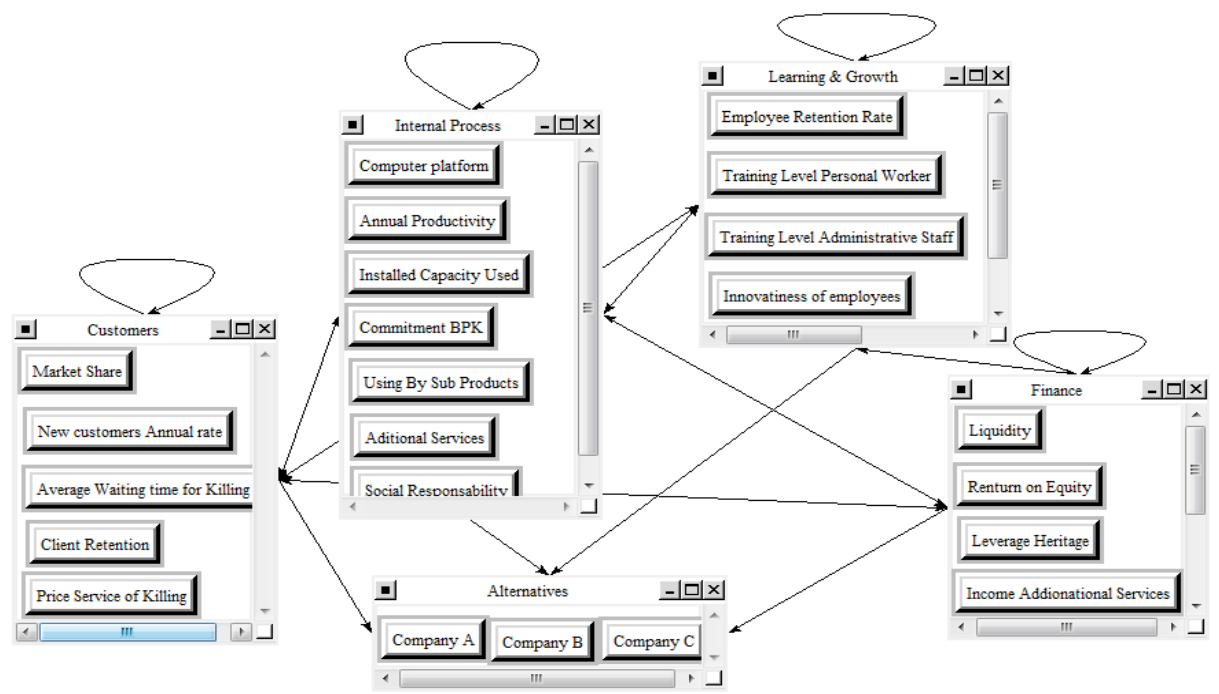

Figure 5. ANP Model for Meat Industry.

Table 2 shows that of the 20 pre-selected indicators, there are 10 indicators that are below $1 \%$ by weight, specifically the last 4 are not considered.

Tabla 2. Indicators of competitiveness for Meat Industry. 


\begin{tabular}{|l|r|l|r|}
\hline \multicolumn{1}{|c|}{ Indicators } & Weight & \multicolumn{1}{c|}{ Indicators } & Weight \\
\hline Annual productivity & $19,17 \%$ & Liquidity & $17,63 \%$ \\
\hline Additional Services & $16,81 \%$ & Training Worker & $11,21 \%$ \\
\hline Employee retention Rate & $9,66 \%$ & Installed Capacity Used & $6,72 \%$ \\
\hline Innovativeness of employees & $6,46 \%$ & Leverage Heritage & $5,90 \%$ \\
\hline Market Participation Rate & $3,40 \%$ & Client Retention & $1,19 \%$ \\
\hline Using By sub-Products & $0,84 \%$ & Commitment BPK & $0,37 \%$ \\
\hline New Customers Annual Rate & $0,24 \%$ & service Killing & $0,18 \%$ \\
\hline Average waiting time for Killing & $0,15 \%$ & Social Responsibility & $0,10 \%$ \\
\hline Return on Equity & $0,00 \%$ & Income Additional Services & $0,00 \%$ \\
\hline Computer platform & $0,00 \%$ & Training Administrative staff & $0,00 \%$ \\
\hline
\end{tabular}

Case 3. The dairy industry is based on the type of final product processed. The sector analized in this case study is pasteurized milk and UHT, which corresponds to 6.5\% of the Venezuelan market. This sector has been affected in the last years due to price regulations along the entire supply chain, large-scale imports from the state and national processing company nationalizations. The value chain for the dairy industry, UHT pasteurized milk is shown in Figure 6.

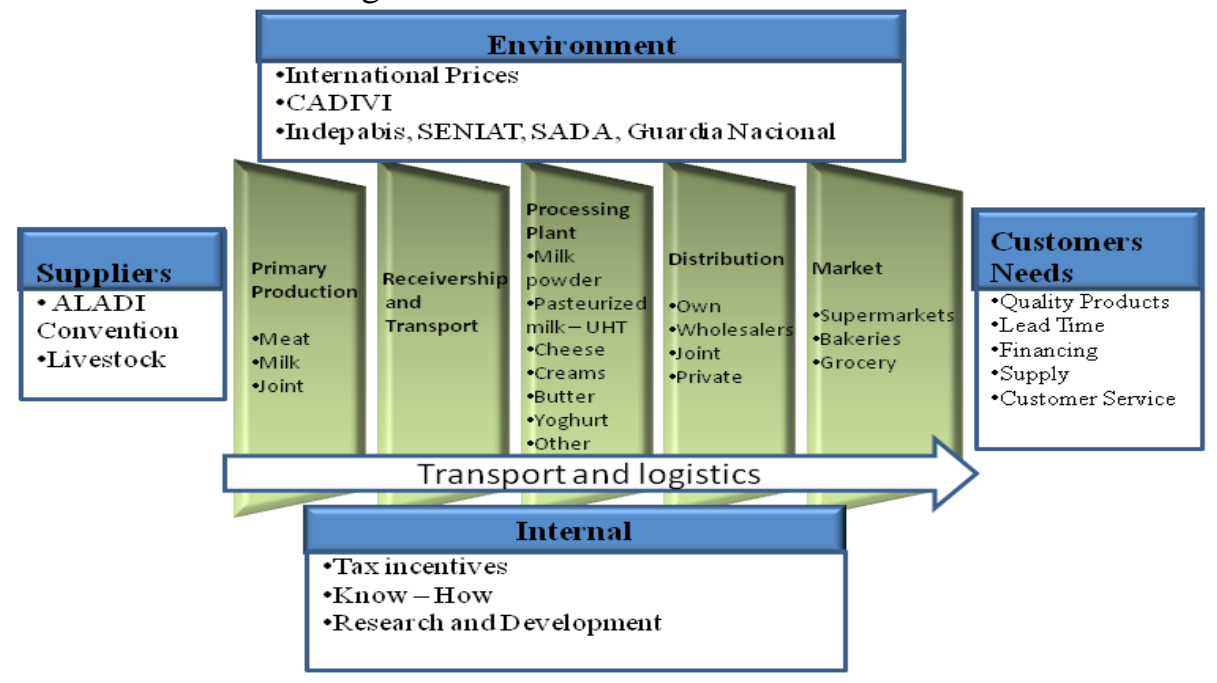

Figure 6. Value Chain of Dairy sector.

Figure 7 show the ANP model. The table 3 shows that $80 \%$ of the weight of indicators focuses on those who represent the perspectives of internal processes and human talent, coupled with market share indicator. 


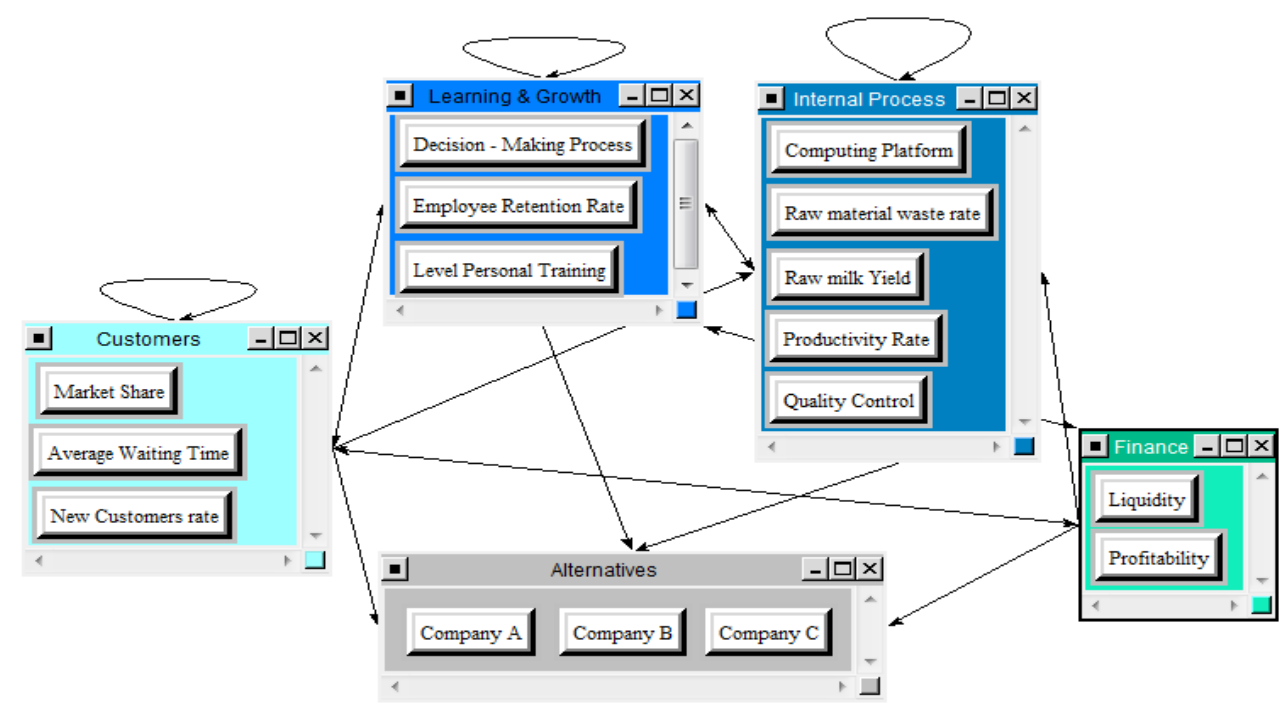

Figure 7. ANP Model for Dairy Sector.

Table 3. Indicators of competitiveness for Dairy Sector.

\begin{tabular}{|l|c|l|c|}
\hline \multicolumn{1}{|c|}{ Indicators } & Weight & \multicolumn{1}{c|}{ Indicators } & Weight \\
\hline Waste rate in raw material & $17,89 \%$ & Decision-Making Process & $17,53 \%$ \\
\hline Raw Milk Yield & $15,09 \%$ & Market Share & $11,60 \%$ \\
\hline Productivity Rate & $9,15 \%$ & Employee Retention & $7,79 \%$ \\
\hline Quality Control & $7,49 \%$ & Profitability & $5,24 \%$ \\
\hline New Customers rate & $2,68 \%$ & Liquidity & $2,13 \%$ \\
\hline Average Waiting Time & $1,89 \%$ & Level Personal Training & $1,04 \%$ \\
\hline Computing Platform & $0,48 \%$ & & \\
\hline
\end{tabular}

\section{Conclusions}

This research shows that the methodology proposed in business sectors is a good approach for Competitive Enterprise Benchmarking that considers all areas of an organization.

One of the key findings of the research is the ranking of the four perspectives, which stands in the three sectors analyzed in Venezuela. The perspective with the strongest impact on competitiveness is Internal Processes and Learning \& Growth. Figure 8 shows the results by sector and their arithmetic mean

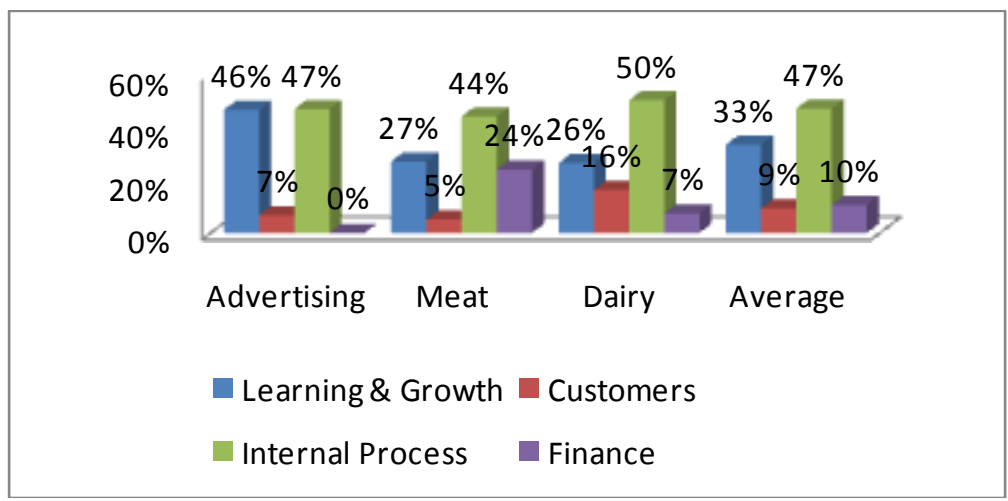

Figure 8. Weight of the Perspectives in the sectors studied. 
On the other hand, the research shows that each sector has its own business model adjusted to the characteristics of the sector. It was very hard to find a dominance within indicators across sectors. However, it appears that the most important competitiveness indicators of the sectors studied are New Services, Annual Productivity, Staff Training, Employee Retention, Market Share and Strategic Decision Making.

\section{REFERENCES}

Augusto, M., Lisboa, J., Yasin, M. y Figueira, J.R. (2006) Benchmarking in a multiple criteria performance context: An application and a conceptual framework. European Journal Operations research 184: 244-254.

Ellis, S. Elnatha, D y Raz, T. (2002) Applying benchmarking: an organizational learning perspective. Human System Management 21: 183-191 IOS Press.

Kaplan, R y Norton, (2000) Cuadro de Mando Integral. Ediciones Gestión 2000, S.A. Barcelona.

Porter, M. (1997) Estrategia Competitiva. Cecsa. (original en ingles 1982). México.

Thakkar, J. Deshmukh, S.G. Gupta, A.D. y Shankar R. (2007). Development of a balanced scorecard. An integrated approach of interpretative Structural Modeling (ISM) and Analytic Network Process (ANP). International Journal of Productivity and Performance Management, 56, 1:25-59.

Saaty, T. (2005) Theory and Applications of the Analytic Network Process. RWS Publications, Pittsburgh, PA. 